\title{
Factors associated with acceptance of peers with mental health problems in childhood and adolescence
}

\author{
Lorraine Swords, ${ }^{1}$ Caroline Heary, ${ }^{2}$ and Eilis Hennessy ${ }^{3}$ \\ ${ }^{1}$ School of Psychology, Trinity College Dublin, Republic of Ireland; ${ }^{2}$ School of Psychology, National University of \\ Ireland Galway, Republic of Ireland; ${ }^{3}$ School of Psychology, University College Dublin, Republic of Ireland
}

\begin{abstract}
Background: Research suggests that children's reactions to peers with mental health problems are related to the maintenance and outcomes of these problems. However, children's perceptions of such peers, particularly those with internalising problems, are neither well researched nor understood. The present study aimed to test a series of models relating socio-demographic and attributional variables to the acceptance of hypothetical boys and girls with attention deficit hyperactivity disorder (ADHD) and depression. Methods: A sample of 595 participants, drawn from five different age-groups spanning early childhood to late adolescence, completed a booklet of questions in response to two vignettes describing the behaviour of hypothetical target peers with depression and ADHD. The sample was drawn from schools randomly selected in the east of Ireland. Results: The models indicated that age and gender of the participant, and the perceived responsibility of the target character for his/her condition, were the three most important predictors of acceptance in all models. However, the relationship between these variables and acceptance varied depending on the gender of the target child and the condition (depression or ADHD) in the models tested. Conclusions: The findings of the study suggest that the relationships between socio-demographic and attributional variables and acceptance of peers with mental health problems depend on the type of mental health problem under consideration. The findings have implications for the development of information and education programmes to improve the integration of children with mental health problems. Keywords: Peer acceptance, mental health problems, ADHD, depression.
\end{abstract}

The prevalence of mental health problems among children and young people living in Europe is such that an estimated one-fifth experience emotional, conduct or hyperkinetic difficulties that affect their functioning at home, at school, and in the larger community (WHO, 2004). The responses and reactions of the peer-group can greatly impact upon the maintenance of these difficulties and long-term outcomes (Deater-Deckard, 2001). However, children's awareness and knowledge of mental health problems is not well researched or understood (Hennessy, Swords, \& Heary, 2008). The available literature suggests that their attitudes, attributions and behavioural intentions towards those affected are mostly negative (e.g., Adler \& Wahl, 1998; Walker, Coleman, Lee, Squire, \& Friesen, 2008; Weiss, 1986, 1994), although educational interventions can have a positive influence (e.g., Naylor, Cowie, Walters, Talamelli, \& Dawkins, 2009).

Still, many unanswered questions exist about the factors that, individually or in combination, influence children's reactions. Although it is recognised that early education about mental health and illness is crucial if stigmatising attitudes and beliefs are to change (Bailey, 1999; Wahl, 2002), such intervention efforts must be informed by an understanding of the determinants of acceptance and rejection. This is

Conflict of interest statement: No conflicts declared. an area that is essentially unstudied in the research literature. Investigations of children's perceptions of internalising conditions and girls with mental health difficulties are also underrepresented relative to those that examine reactions towards externalising conditions and affected boys.

The present study sets out to address the shortcomings of the existing published research by investigating how a model incorporating sociodemographic and attributional variables can predict acceptance of boys and girls presenting with an internalising and an externalising psychological disorder. But which variables might predict acceptance? The following paragraphs outline those that have been suggested in the literature and thus have been selected to comprise the model under investigation.

\section{Socio-demographic variables: age, gender and socio-economic status (SES)}

Research has shown a relationship between age and children's attitudes towards and understanding of psychologically disordered peers, suggesting that older children are more positive and hold fewer negative stereotypes (e.g., Whalen, Henker, Dotemoto, \& Hinshaw, 1983) and also display greater knowledge and understanding of mental illness (e.g., Poster, 1992). Another socio-demographic variable 
worthy of further investigation is gender. Gender might be important in relation to children's responses in three ways: children's attitudes and beliefs might vary as a function of their own gender (Campbell, Ferguson, Herzinger, Jackson, \& Marino, 2004; Nowiki, 2006), attitudes and beliefs might vary as a function of the gender of the child displaying the problem (e.g., Connor, Serbin, \& Ender, 1978), and attitudes and beliefs might be a function of the interaction between the child's own gender and the gender of the child displaying the problem (e.g., Guite, Walker, Smith, \& Garber, 2000; Woodward, 1995). Few studies have investigated the influence of a child's SES on his or her attitudes, although Roberts, Johnson, and Beidleman (1984) have noted how SES may impact upon understanding of mental illness and perceptions of different conditions.

\section{Attributional variables}

Perceived responsibility. Theory and research have suggested that children's attitudes and behavioural intentions towards peers with various mental health problems are at least partially determined by their understanding of the factors causing the problem. Attribution theory proposes that beliefs about perceived responsibility can influence interpersonal affect, which, in turn, can influence overt behaviours or behavioural intentions (Weiner, 1995). Juvonen (1991) and Corrigan and colleagues (2007) reported how children's increasing beliefs about peers' responsibility for their deviant behaviours were linked with reports of increased anger and reduced sympathy. Such beliefs and reactions were then predictive of negative social consequences such as rejection and a lack of social support.

Beliefs about stress. Research investigating children's attitudes towards depressed peers has also suggested that responses are more positive towards peers who have recently experienced stress (Peterson, Mullins, \& Ridley-Johnson, 1985). Affected children are deemed less responsible for their condition, and rejection is a less likely outcome (Little \& Garber, 1995).

Beliefs about prognosis. Children's awareness of and views on the stability and durability of a condition can impact on their attitudes and behavioural intentions. Weriserbs and Gottlieb (2000), for example, noted that a hypothetical peer presented with a temporary physical disability received more favourable responses than a peer presented with permanent difficulties. Giles (2003) and Giles and Heyman $(2003,2004)$ with colleagues have investigated children's beliefs that some behaviours are stable and innate. If these behaviours are problematic, such 'essentialist' thinking has been associated with poorer attitudes and less acceptance. It appears to occur particularly when children believe that a wrongdoing was committed intentionally (De Alencar, Maciel, Fernandes, \& Patriota, 1984), resulting in target peers being assigned trait labels such as 'nasty' or 'bad'.

\section{The present study}

The present study aims to highlight the factors that contribute to or hinder children's acceptance of peers with two specified types of mental health difficulty: depression (internalising condition) and ADHD (externalising condition). The decision to focus on these conditions was based on their prevalence among children and adolescents (Ford, Goodman, \& Meltzer, 2003; Lynch, Mills, Daly, \& Fitzpatrick, 2006). For example, in Lynch et al. (2006) $15.6 \%$ of 12 - to 15 -year-olds met criteria for a current psychiatric disorder. The most common internalising condition experienced was affective disorders (affecting 4.5\%), while the most common externalising condition experienced was ADHD (affecting 3.7\%). Findings should make a significant contribution to the international literature on children's understanding of psychological problems by permitting a direct comparison of the factors predicting acceptance of peers with internalising and externalising disorders and by focusing on the significance of gender (of participant and target) for acceptance.

From reviewing theory and research in the area, the conceptual model outlined in Figure 1 was specified a priori. The variables that lend themselves to further investigation are: the participant's age, gender, SES, beliefs about responsibility for psychological disorders (as outlined in attribution theory), beliefs about recent life stress as a cause of the conditions (as linked with attribution theory), and beliefs about the stability of associated behaviours (as outlined in psychological essentialism), as assessed through predictions of future prognoses.

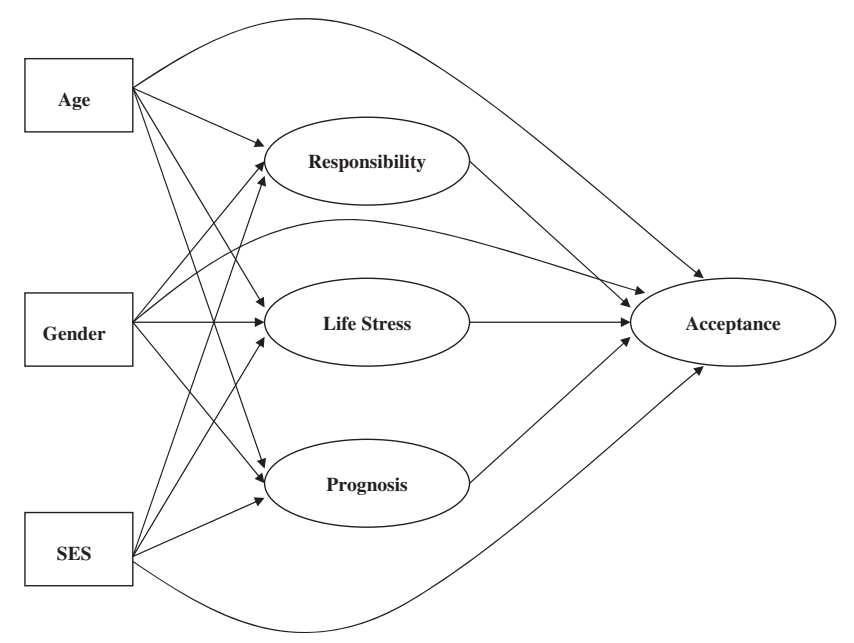

Figure 1 Conceptual model of the direct and indirect relationships between factors predicting acceptance and acceptance 
The effect of each of these variables on children's acceptance is examined, as is the influence of the measured variables (participants' age, gender and SES) on responsibility, life stress and prognosis. The roles of responsibility, recent life stress and prognosis as mediating variables between age, gender and SES and acceptance will then be investigated.

The proposed conceptual model is examined separately for the ADHD and the childhood depression conditions, based on the finding that children and adolescents may differ in their reactions to different mental health problems (Jorm \& Wright, 2008; Phelan \& Basow, 2007; Walker et al., 2008). In order to investigate any impact that the gender of the target child may have on participants' responses, for each condition a model for male targets and a model for female targets will be considered. Ethical approval for the research was granted by the Human Research Sub-Committee of the Research Ethics Committee of University College Dublin, Ireland.

\section{Method}

\section{Participants}

Participants consisted of 595 children and adolescents recruited from 20 randomly selected primary schools and secondary schools from the Irish Department of Education and Science published lists of schools in Leinster, the eastern region of Ireland. Boys and girls were sampled from three different primary school grades (with average ages of 6, 9 and 12 years) and from two different secondary school grades (with average ages of 14 and 16 years). See Table 1 for a detailed account of participant numbers, ages and gender for each school grade.

\section{Materials}

Data collected for the present study was part of a larger study investigating children's perceptions of psychological disorders in their peers. Participants completed a series of open and closed questions following short descriptions of hypothetical peers displaying the target behaviours (depression and ADHD - see Appendix A for sample vignettes). The first set of questions assessed participants' beliefs about the causes of the target behaviours. Data from these questions were subjected to factor analyses and resulted in the development of the Children's Attributions about Psychological Problems in their Peers (CAPPP) Scale (detailed in Swords, Hennessy, \& Heary, 2010a). Items from this scale and

Table 1 Participant numbers, gender and age by school year

\begin{tabular}{lccccc}
\hline & & & \multicolumn{3}{c}{ Mean age } \\
Year & Number & Male & Female & (years) & SD \\
\hline 2 & 96 & 57 & 39 & 6.33 & 4.53 \\
5 & 104 & 59 & 45 & 9.33 & 5.49 \\
8 & 107 & 66 & 41 & 12.42 & 5.52 \\
10 & 153 & 73 & 80 & 14.42 & 5.13 \\
13 & 135 & 69 & 66 & 16.67 & 9.22 \\
\hline
\end{tabular}

other questions taken from the booklet to comprise the conceptual model to be tested are detailed below. Please see Table 2 for example items for each of the measured variables. doi: 10.1111/j.1365-2214.2010.01151.x

Responsibility: 'Responsibility' is a latent factor. It comprised the volition subscale from the CAPPP and a direct question on responsibility: 'Do you think that [target child] wants to act the way that he/she does?' The range of scores for the volition subscale was from 3 to 12 and for the responsibility item from 1 to 4 . For both measures, higher scores indicated beliefs about higher responsibility for displayed behaviour.

Life stress: The life stress factor is also latent. It comprised the life stress subscale of the CAPPP. While the volition subscale items noted above were entered into the model in a 'parcel' along with the single responsibility question, the life stress subscale items are the only measure of the life stress latent variable and will thus be entered into the model as individual items. Scores ranged from 4 to 16 for the ADHD condition and from 4 to 20 for the depression condition (the life stress subscale of the CAPPP contains an extra item for internalising conditions). Higher scores indicated a greater belief that behaviour was due to experiencing recent life stress.

Prognosis: 'Prognosis' is latent and comprised two measured variables from the questionnaire booklet: 'What do you think [target child] will act like next year?' and 'What do you think [target child] will act like when he/she grows up?' Scores ranged from 1 to 3, with higher scores indicating a belief in a more favourable prognosis.

Acceptance: The latent variable of acceptance comprised the three subscales of the Shared Activity Questionnaire (SAQ: Morgan, Walker, Bieberich, \& Bell, 1996), a measure of children's behavioural intentions towards target characters across three broad dimensions of interactions: academic, general social, and active recreational. Scores range from 8 to 24, with higher scores indicating greater behavioural intentions to interact with the target peer.

In addition to the above, the following demographic variables were incorporated into the model.

Age: Participants' ages were entered in months. Ages range from 66 months to 241 months.

Gender: Males were coded as ' 0 ' and females were coded as ' 1 '.

SES: Parental education was used as a proxy for coding SES, which was based upon the highest level of education attained by the participants' parents/ guardians, as indicated on the study consent form. Lower SES was defined as second-level schooling completion certificates or less and is assigned the code of ' 0 '. Higher SES was defined as any post-second-level certificates, diplomas or degrees and is assigned the code of ' 1 '.

\section{Procedure}

Children and adolescents with written parental consent who also verbally assented to take part were randomly presented with one of two versions of the questionnaire booklet. Version one contained a male ADHD vignette character and a female depression vignette character while version two contained a female ADHD vignette 
Table 2 Descriptive statistics for questionnaire items used in ADHD and Depression SEM models

\begin{tabular}{|c|c|c|c|c|c|c|c|}
\hline \multirow[b]{2}{*}{ Latent variable } & \multirow[b]{2}{*}{ Measured variable } & \multirow[b]{2}{*}{ Range } & \multirow[b]{2}{*}{ Model } & \multicolumn{2}{|c|}{ ADHD } & \multicolumn{2}{|c|}{ Depression } \\
\hline & & & & Mean (SD) & $\begin{array}{l}\text { Factor } \\
\text { loading }\end{array}$ & Mean (SD) & $\begin{array}{l}\text { Factor } \\
\text { loading }\end{array}$ \\
\hline \multirow[t]{4}{*}{ Responsibility } & $\begin{array}{l}\mathrm{y}_{1} \text { Responsibility } \\
\text { Question }\end{array}$ & $1.00-4.00$ & Male & $2.25(0.898)$ & 0.63 & $1.79(0.986)$ & 0.63 \\
\hline & $\begin{array}{l}\text { 'Do you think that [target } \\
\text { child] wants to act the } \\
\text { way that s/ he does?' }\end{array}$ & & Female & $2.22(0.980)$ & 0.36 & $1.84(0.949)$ & 0.82 \\
\hline & $\begin{array}{l}\mathrm{y}_{2} \text { CAPPP Volition } \\
\text { Subscale }\end{array}$ & $3.00-12.00$ & Male & $7.90(2.367)$ & $0.44^{*}$ & $6.08(2.320)$ & $0.66^{*}$ \\
\hline & $\begin{array}{l}\text { E.g. '[Target child] acts } \\
\text { this way because s/ he } \\
\text { wants to and thinks it's } \\
\text { cool' }\end{array}$ & & Female & $7.38(2.224)$ & $0.26^{*}$ & $5.76(2.238)$ & $0.46^{*}$ \\
\hline \multirow[t]{9}{*}{ Recent life stress } & $\mathrm{y}_{3}$ CAPPP Part 5 & $1.00-4.00$ & Male & $2.70(0.932)$ & 0.25 & $2.99(0.859)$ & 0.39 \\
\hline & $\mathrm{y}_{4}$ CAPPP Part 10 & $1.00-4.00$ & Male & $2.49(0.987)$ & $0.80^{*}$ & $2.78(0.964)$ & $0.40 *$ \\
\hline & $\begin{array}{l}\text { '[Target child] acts this } \\
\text { way because s/he is } \\
\text { being bullied or ignored } \\
\text { by other teenagers' }\end{array}$ & & Female & $2.55(0.977)$ & $0.27^{*}$ & $2.91(0.917)$ & $0.42 *$ \\
\hline & $\mathrm{y}_{5}$ CAPPP Part 12 & $1.00-4.00$ & Male & $2.84(0.819)$ & $0.22 *$ & $3.14(0.882)$ & $0.62 *$ \\
\hline & $\begin{array}{l}\text { 'Tharget child] behaves } \\
\text { this way because s/he } \\
\text { is going through a } \\
\text { difficult time in his/her } \\
\text { life' }\end{array}$ & & Female & $2.90(0.855)$ & $0.28^{*}$ & $3.25(0.738)$ & $0.64^{*}$ \\
\hline & $\mathrm{y}_{6}$ CAPPP Part 14 & $1.00-4.00$ & Male & $\mathrm{N} / \mathrm{A}$ & $\mathrm{N} / \mathrm{A}$ & $2.66(0.877)$ & $0.70^{*}$ \\
\hline & $\begin{array}{l}\text { 'TTarget child] does these } \\
\text { things because s/he's } \\
\text { nervous, worried or ex- } \\
\text { cited' }\end{array}$ & & Female & & & $2.80(0.857)$ & $0.69 *$ \\
\hline & $\mathrm{y}_{6}$ CAPPP Part 15 & $1.00-4.00$ & Male & $2.54(0.956)$ & $0.29 *$ & $2.83(0.950)$ & $0.49^{*}$ \\
\hline & $\begin{array}{l}\text { 'Somebody in [target } \\
\text { child's] family might } \\
\text { have died and so s/he } \\
\text { acts like this' }\end{array}$ & & Female & $2.44(0.994)$ & $0.25^{*}$ & $2.87(0.931)$ & $0.58 *$ \\
\hline \multirow[t]{4}{*}{ Prognosis } & $\mathrm{y}_{8}$ Prognosis Question 1 & $1.00-3.00$ & Male & $2.19(0.830)$ & $0.94^{*}$ & $2.25(0.838)$ & 0.99 \\
\hline & $\begin{array}{l}\text { 'What do you think } \\
\text { target child] will act like } \\
\text { next year?' }\end{array}$ & & Female & $2.25(0.798)$ & 0.24 & $2.31(0.835)$ & 0.98 \\
\hline & y9 Prognosis Question 2 & $1.00-3.00$ & Male & $2.52(0.788)$ & 0.40 & $2.55(0.770)$ & $0.55^{*}$ \\
\hline & $\begin{array}{l}\text { 'What do you think } \\
\text { target child] will act like } \\
\text { when he/she grows } \\
\text { up?' }\end{array}$ & & Female & $2.54(0.789)$ & 0.98 & $2.56(0.777)$ & $0.47^{*}$ \\
\hline \multirow[t]{6}{*}{ Acceptance } & $\begin{array}{l}\mathrm{y}_{10} \text { SAQ Academic } \\
\text { Subscale }\end{array}$ & $8.00-24.00$ & Male & $15.41(4.563)$ & $0.75^{*}$ & $16.52(4.954)$ & $0.86^{*}$ \\
\hline & $\begin{array}{l}\text { E.g. 'Sit next to [target } \\
\text { child] in class' }\end{array}$ & & Female & $14.96(4.517)$ & $0.38 *$ & $17.64(4.975)$ & $0.83^{*}$ \\
\hline & $\begin{array}{l}\mathrm{y}_{11} \text { SAQ Active } \\
\text { Recreational Subscale }\end{array}$ & $8.00-24.00$ & Male & $16.64(4.650)$ & $0.86^{*}$ & $17.30(4.940)$ & $0.93^{*}$ \\
\hline & $\begin{array}{l}\text { E.g. 'Pick [target child] to } \\
\text { be on my soccer team' }\end{array}$ & & Female & $16.06(4.908)$ & $0.43^{*}$ & 17.94(4.962) & $0.91^{*}$ \\
\hline & $\begin{array}{l}\mathrm{y}_{12} \text { SAQ General Social } \\
\text { Subscale }\end{array}$ & $8.00-24.00$ & Male & $16.54(4.231)$ & 0.94 & $17.49(4.875)$ & 0.95 \\
\hline & $\begin{array}{l}\text { E.g. 'Invite [target child] } \\
\text { to my birthday party' }\end{array}$ & & Female & $16.17(4.601)$ & 0.47 & $18.37(4.841)$ & 0.95 \\
\hline
\end{tabular}

* indicates statistically significant $(p<0.05)$ factor loadings.

character and a male depression vignette character. Participants in the secondary school (14- and 16-yearolds) and the oldest group of primary school children (12-year-olds) were instructed to work through the booklet by themselves, but were invited to ask the researcher for assistance at any stage. Pilot-testing indicated how the younger participants might be assisted and so the 9-year-olds completed the scale in 
small groups with the help of the researcher, while the 6-year-olds were taken through the questions on a oneto-one basis with the researcher who read the vignettes, items and response options aloud and transferred replies onto the booklet. All testing took place in participants' classrooms during the school day. At secondary school level, introducing and completing the questionnaire usually took the most part of one 40-minute class period. At primary school level, times varied from 30 minutes per child, when interviewing the youngest (6-year-old) participants, to 45 minutes for an entire class, as with the 12-year-old students.

\section{Plan for data analysis}

This study aimed to develop a theoretical model of the relative contributions of socio-demographic and attributional variables in children's acceptance of psychologically disordered peers with ADHD and depression. This model was specified a priori and estimated using LISREL 8.3 for the ADHD data and the depression data separately. Within each condition (ADHD and depression), two models were tested: one with only male target characters and one with only female target characters. Covariance matrices were computed using PRELIS2.3 and analysed using maximum likelihood estimation.

\section{Results}

In Figure 2 typical path diagram conventions are followed so that latent variables are represented as circles and measured items $\left(\mathrm{y}_{1}-\mathrm{y}_{12}\right)$ are represented as boxes. In order to lessen the complexity of the diagram, the measurement error for each item has been omitted. Arrows connecting the latent variables and the items that comprise them are factor loadings. Arrows between latent variables are regression coefficients.

In evaluating the success of both models, guidelines suggested by Hoyle and Panter (1995) were followed and so chi-square tests were consulted

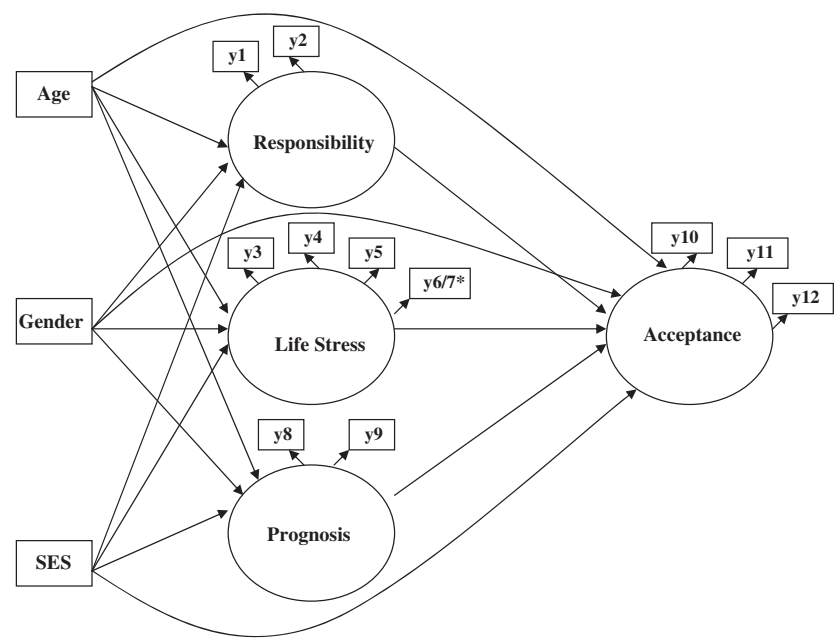

Figure 2 Path diagram of the direct and indirect relationships between factors predicting acceptance and acceptance. ${ }^{*} y 7$ is the extra item that comprises the Life Stress subscale of the CAPPP for the depression condition along with the Incremental Fit Index (IFI), the Comparative Fit Index (CFI) and indices based on the proportion of variance accounted for, such as the Goodness of Fit Index (GFI). Additionally, the root mean square error of approximation (RMSEA) value with $90 \%$ confidence intervals is reported along with the standardised root mean square residual (SRMR).

The estimated ADHD and depression models for male and female target peers all performed well on measures of model 'fit' with the empirical covariance matrices created from the study's data. In each case, the chi-square values were appropriate (the ratio of the chi-square to the degrees of freedom was between two and five) and the fit indices all exceed the recommended value of 0.90 . In addition, the RMSEA and SRMR values are less than the recommended value of 0.08 .

Descriptive statistics for the observed items from the questionnaire used in the SEM models for ADHD and depression to comprise latent variables are presented in Table 2. The standardised factor loadings for each of the measured variables on their respective latent variables are also listed.

\section{ADHD models}

When the target peer was male, age $(\beta=0.21 ; p<$ $0.01)$ and gender $(\beta=0.15 ; p<0.05)$ had significant effects on acceptance. Thus, older children were more positive than younger children and girls were more positive than boys. The latent variables of responsibility $(\beta=-0.31 ; p<0.05)$, life stress $(\beta=$ $0.28 ; p<0.05)$ and prognosis $(\beta=0.22 ; p<0.05)$ predicted acceptance. Greater beliefs about the male peer's responsibility for his condition were associated with less acceptance. Beliefs that the male peer's condition was due to recent life stress and had a favourable prognosis for the future were associated with more acceptance.

Age also affected beliefs about responsibility $(\beta=$ $-0.21 ; p<0.05)$ and prognosis $(\beta=-0.23 ; p<0.01)$ towards the male peer, with older children believing him to be less responsible for his condition but also less likely to improve in the future (Figure 3). In addition, older children were less likely to endorse life stress $(\beta=-0.39 ; p<0.01)$ as a cause of his condition. Age was found to have a low significant indirect effect on acceptance through responsibility $(\beta=0.06 ; p<0.05)$. None of the other regression coefficients were statistically significant.

When the target peer was female, age $(\beta=0.20$; $p<0.01)$ and gender $(\beta=0.39 ; p<0.01)$ again had significant effects on acceptance (Figure 4). Thus, older children were more positive than younger children and girls were more positive than boys. Acceptance was not significantly predicted, either directly or indirectly, by any of the other variables. A significant effect was noted between gender and prognosis $(\beta=0.58 ; p<0.05)$, where girls believed more strongly that their female peer would improve her 


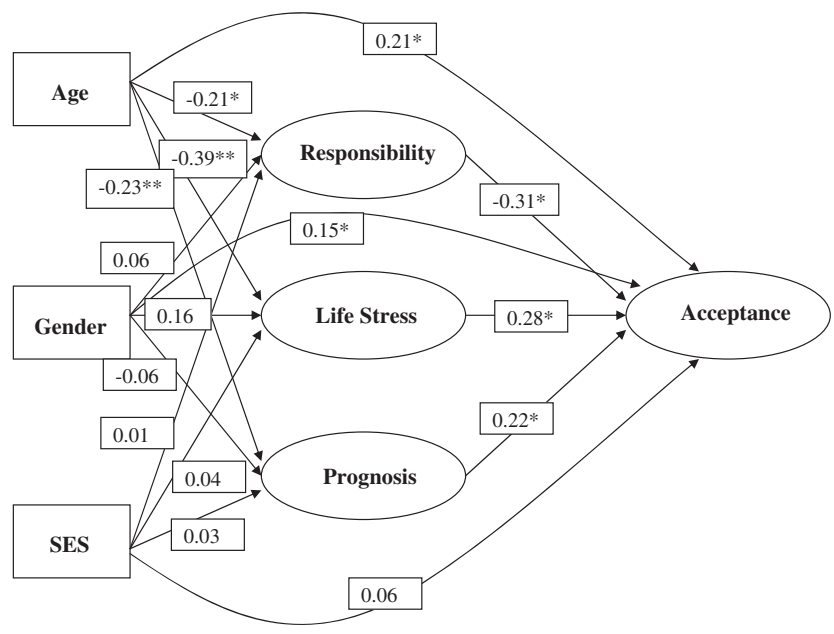

Figure 3 Standardised solutions for ADHD model with male target peers. ${ }^{*}=p<0.05 ; * *=p<0.01$

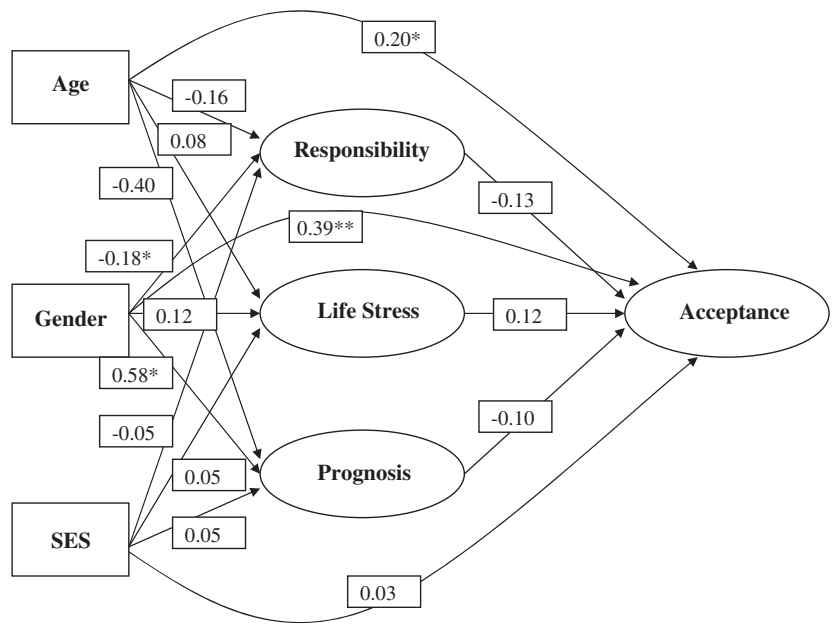

Figure 4 Standardised solutions for ADHD model with female target peers. ${ }^{*}=p<0.05 ;{ }^{*}=p<0.01$

behaviours in the future, and gender and responsibility $(\beta=-0.18 ; p<0.05)$, where girls held the female target character less responsible for her behaviour.

\section{Depression models}

When the target peer was male, age $(\beta=-0.15$; $p<0.05$ ) had a significant effect on acceptance, with older participants reporting less favourable attitudes (Figure 5). Only the latent variable of responsibility $(\beta=-0.33 ; p<0.01)$ predicted acceptance, where greater beliefs about responsibility resulted in less acceptance.

Age had an effect on responsibility $(\beta=-0.23$; $p<0.01)$, life stress $(\beta=0.34 ; p<.01)$ and prognosis $(\beta=-0.22 ; p<0.01)$. Thus, older participants were more likely to assign the male peer less responsibility and believe that symptoms were due to recent life stress, but believe that prognosis was not favourable. Gender affected responsibility $(\beta=-0.21 ; p<$ $0.01)$ and life stress $(\beta=0.14 ; p<0.05)$, with girls assigning less responsibility to the hypothetical male peer and believing more that his symptoms might be

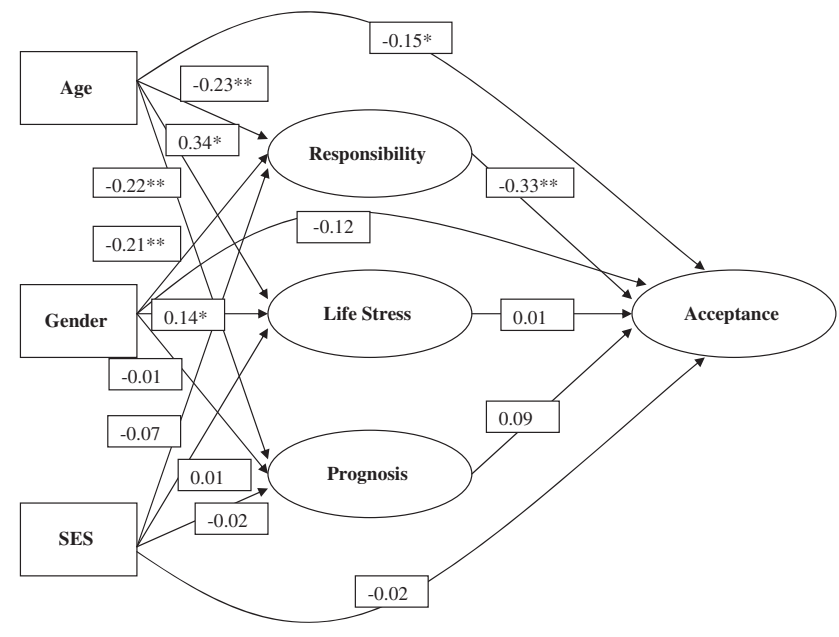

Figure 5 Standardised solutions for depression model with male target peers. ${ }^{*}=p<0.05 ;{ }^{* *}=p<0.01$

due to recent life stress. Both age and gender indirectly predicted acceptance through responsibility $(\beta=0.08 ; p<0.05$ and $\beta=0.07 ; p<0.05$, respectively). None of the other regression coefficients were statistically significant.

When the target peer was female, gender $(\beta=0.45$; $p<0.01$ ) had a significant effect on acceptance (Figure 6). Thus, girls were more positive than boys towards the female depressed peer. Acceptance was not significantly predicted by any of the other variables.

Age had an effect on life stress $(\beta=0.42 ; p<0.01)$ and prognosis $(\beta=-0.16 ; p<0.01)$. Thus, older participants were more likely to believe that symptoms of depression were due to recent life stress but also believe in an unfavourable prognosis. Again, gender affected responsibility $(\beta=-0.14 ; p<0.05)$ and life stress $(\beta=0.16 ; p<0.05)$, with girls assigning less responsibility to the hypothetical female peer and believing more that her symptoms might be due to recent life stress. None of the other regression coefficients were statistically significant.

A summary of the findings and a discussion of their implications with regard to theory and practice will be provided in the next section of this paper. Con-

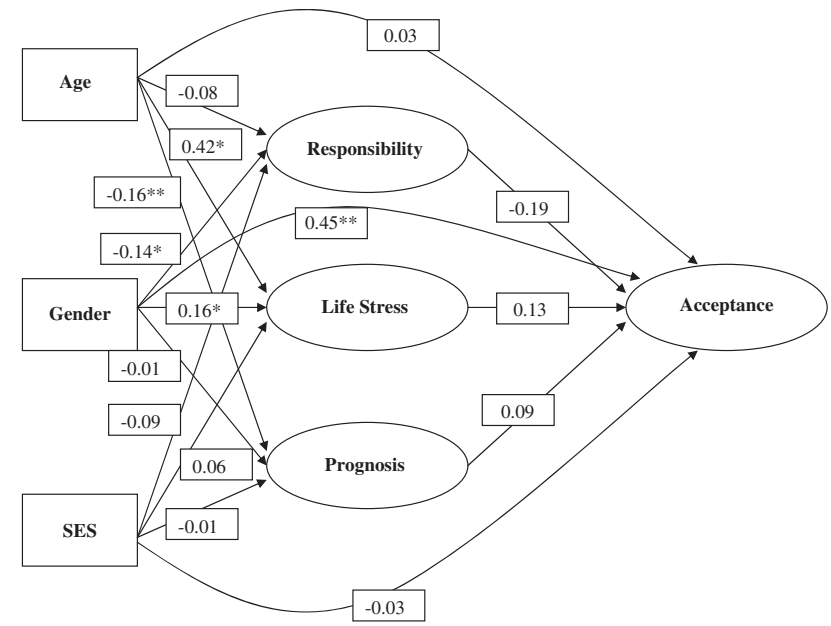

Figure 6 Standardised solutions for depression model with female target peers. ${ }^{*}=p<0.05 ; * *=p<0.01$ 
sidering the very low values ( $\beta$ less than 0.1 ) found through analyses of indirect effects, the discussion will focus on the factors that directly impacted upon children's acceptance of hypothetical peers with ADHD and depression. The effect of age, gender and SES on the mediating variables of responsibility, life stress and prognosis will also be evaluated.

\section{Discussion}

This study aims to test a series of conceptual models of the factors that contribute to children's acceptance of peers with mental health difficulties. In doing so, the authors have tested models for two of the more common mental health problems during childhood, namely depression and ADHD. These different models allow one to reflect on whether there are shared or unique contributory factors in the acceptance of peers with internalising and externalising disorders. In addition, the authors have examined children's attitudes towards a male and female version of each condition, in recognition of the role that gender can play in children's peer relationships.

Results indicated that the three most important predictors of acceptance of peers with psychological difficulties were age, gender of the participant and perceived responsibility. However, the role of these variables was found to vary depending on the condition and the gender of the target child. Age was a significant predictor of acceptance for three of the four models (both the male and female character with ADHD; and the male character with depression). Within the ADHD models, older participants tended to give higher ratings of acceptance. In contrast, for the male depressed character, older age predicted less acceptance of the target character. A further important predictor of acceptance across three of the four models was the gender of the participant. Female participants gave higher ratings of acceptance for both male and female characters with ADHD and the female character with depression. Finally, greater belief in the target child's responsibility for his condition was associated with less acceptance for the male target characters only (both ADHD and depression). Indeed, beta values indicate that perceived responsibility was the most important predictor of acceptance when the target character was male. Further work is required to explore why attributions of controllability have a greater influence in judgements of boys in comparison to girls.

Across all models, SES was not significantly related to acceptance or indeed any of the mediating variables. However, the measurement of SES within the current study was crudely based on a dichotomous variable (high/low), so further work using a more differentiated method of measurement may be required.

The two remaining mediating variables examined in this study, prognosis and life stress, were only significant predictors of acceptance for the male target character with ADHD. Within this model, greater endorsement of life stress amongst the participants and beliefs that ADHD had a favourable prognosis were associated with greater acceptance.

In considering the above findings, it is important to reflect on the method used. The current study depicts hypothetical peers with mental health difficulties, focusing on behavioural descriptions and avoiding the use of labels. Unlike much previous research, the vignettes have been validated through ratings of clinical psychologists (Hennessy \& Heary, 2009). However, while vignettes are a common technique used in the literature, the responses provided may not reflect children's actual behavioural responses to real-life peers in real-life situations. In one of the few studies comparing children's responses to hypothetical and actual peers, more favourable responses were reported in the hypothetical scenarios (Juvonen, 1991). Thus caution must be exercised in over-generalising these findings.

While previous research has examined an array of individual socio-demographic and attributional variables as potential predictors of acceptance for different types of mental health conditions, this is one of the few studies to examine the combination of these variables within an individual study. In doing so, the current study was able to assess the direct and indirect relationships between each of these predictors and the outcome variable of children's behavioural intentions. Furthermore, these models focused on specific common childhood mental health difficulties, in comparison to other published studies which test models of stigma towards peers labelled as having the general term 'mental illness' (e.g., Corrigan et al., 2007). Furthermore, the measures in the current study and the associated vignettes were specifically derived for children and young people on the basis of previous qualitative research, in contrast to some previous work which has tended to draw upon adult literature.

However, a number of steps can be taken in moving this topic of investigation forward. The current models still leave a significant proportion of variance in behavioural intentions towards peers with depression or ADHD unaccounted for. Expansion of this model to include other factors, such as the quality of previous contact, could be considered. Also, because the development of the models was theory-driven rather than exploratory, no post-hoc modifications occurred and no alternative models were investigated. Future research might examine alternatives to what is currently proposed. Finally, the current study focuses on one component of attitudes, namely, behavioural intentions, but does not incorporate cognitive or emotional components. In addition, it assesses only children's behavioural intentions and not their actual behaviour. The applicability of this model to other attitudinal components (using both implicit and explicit measures) and actual behavioural outcomes could be avenues for future investigation. 
Despite, the above limitations, the current findings have a number of significant implications. In particular, the observed negative relationship between age and acceptance towards the male character with depression deserves consideration. It is contrary to the increasing tolerance and acceptance that was observed amongst older peers towards both male and female characters with ADHD and is particularly worrying considering how depressive disorders confer an increased risk of suicidal behaviour and, internationally, suicide is a leading cause of death in the 10to 24-year-old age group, with more boys than girls taking their own lives (Centre for Disease Control, 2009; Wasserman, Cheng, \& Jiang, 2005). The responses of peers to such difficulties are particularly important, as research suggests that friends are one of the more common sources of support when mental health issues arise (Swords, Hennessy, \& Heary, 2010b). Creating a peer environment that is inclusive and accepting remains a fundamental challenge.

\section{Conclusion}

The current study highlights both common and unique predictors of acceptance towards peers with ADHD and depression. However, even when common patterns emerge they are not always uniform across all participants. Judgements of children and adolescents with mental health difficulties vary depending on the age and gender of the evaluator. A key finding of the current study is that children do not have unitary conceptions of mental illness; but make clear distinctions in their attributions and behavioural responses when faced with peers with different types of psychological difficulties. Thus, our efforts to understand children's reactions to peers with psychological difficulties and our efforts to promote positive interactions within the peer group must take this into account.

\section{Acknowledgements}

This research was funded with a grant from the Irish Research Council for the Humanities and Social Sciences. The authors grateful acknowledge the assistance of all the school, parents and pupils who took part in the research.

\section{Correspondence to}

Lorraine Swords, Children's Research Centre, Trinity College Dublin, Dublin 2, Republic of Ireland; Tel: 01 8963638; Email: swords1@tcd.ie

\section{Key points}

- Research has established that children displaying mental health problems continually attract negative evaluations from peers, yet the sparse literature in this area permits only a limited insight into the factors that influence such attitudes.

- The present study indicates that the age and gender of peers and how responsible they perceive a target child to be for his/her condition were the three most important predictors of acceptance. However, the relationship between these variables and acceptance varied depending on the gender of the target child and the condition he/she displayed.

- Findings enhance our understanding of the determinants of children's attitudes towards mental health problems and represent an important foundation for the development of educational interventions aimed at promoting acceptance.

\section{References}

Adler, A.K., \& Wahl, O.F. (1998). Children's beliefs about people labelled mentally ill. Journal of American Orthopsychiatric Association, 68, 321-326.

Bailey, S. (1999). Young people, mental illness, and stigmatization. Psychiatric Bulletin, 23, 107-110.

Campbell, J.M., Ferguson, J.E., Herzinger, C.V., Jackson, J.N., \& Marino, C.A. (2004). Combined descriptive and explanatory information improves peers' perceptions of autism. Research in Developmental Disabilities, 25, 321-339.

Centre for Disease Control and Prevention. (2009). Webbased Injury Statistics Query and Reporting System (WISQARS). Retrieved November 12, 2010, from http://www. cdc.gov/violenceprevention/pub/youth_suicide.html

Connor, J.M., Serbin, L.A., \& Ender, R.A. (1978). Responses of boys and girls to aggressive, assertive and passive behaviors of male and female characters. Journal of Genetic Psychology, 133, 59-69.
Corrigan, P.W., Watson, A., Otey, E., Westbrook, A., Gardner, A., Lamb, T., \& Fenton, W. (2007). How do children stigmatize people with mental illness? Journal of Applied Social Psychology, 37, 1405-1412.

De Alencar, E.M., Maciel, D.M., Fernandes, M.T., \& Patriota, T.G. (1984). Reactions of children to trangressors and victims of injustice: Replication of a study. Arquivos Brasileiros de Psicologia, 36, 24-31.

Deater-Deckard, K. (2001). Annotation: Recent research examining the role of peer relationships in the development of psychopathology. Journal of Child Psychology and Psychiatry, 42, 565-579.

Ford, T., Goodman, R., \& Meltzer, H. (2003). The British Child and Adolescent Mental Health Survey 1999: The prevalence of DSM-IV disorders. Journal of the American Academy of Child and Adolescent Psychiatry, 42, 1203-1211.

Giles, J.W. (2003). Children's essentialist beliefs about aggression. Developmental Review, 23, 413-443.

Giles, J.W., \& Heyman, G.D. (2003). Preschooler's beliefs about the stability of antisocial behaviour: Implications 
for navigating social challenges. Social Development, 12, 182-197.

Giles, J. W., \& Heyman, G.D. (2004). Conceptions of aggression and withdrawal in early childhood. Infant and Child Development, 13, 407-421.

Guite, J.W., Walker, L.S., Smith, C.A., \& Garber, J. (2000). Children's perceptions of peers with somatic symptoms: The impact of gender, stress, and illness. Journal of Paediatric Psychology, 25, 125-135.

Hennessy, E., \& Heary, C. (2009). The development of children's understanding of common psychological problems. Child and Adolescent Mental Health, 14, 42-47.

Hennessy, E., Swords, L., \& Heary, C. (2008). Children's understanding of psychological problems displayed by their peers: Review of the literature. Child: Care, Health and Development, 34, 4-9.

Hoyle, R.H., \& Panter, A.T. (1995). Writing about structural equation models. In R.H. Hoyle (Ed.), Structural equation modeling: Concepts, issues and applications. London: Sage.

Jorm, A.F., \& Wright, A. (2008). Influences on young people's stigmatising attitudes towards peers with mental disorders: National survey of young Australians and their parents. The British Journal of Psychiatry, 192, 144-149.

Juvonen, J. (1991). Deviance, perceived responsibility, and negative peer reactions. Developmental Psychology, 27, 672-681.

Little, S.A., \& Garber, J. (1995). Aggression, depression, and stressful life events predicting peer rejection in children. Development and Psychopathology, 7, 845-856.

Lynch, F., Mills, C., Daly, I., \& Fitzpatrick, C. (2006). Challenging times: Prevalence of psychiatric disorders and suicidal behaviours in Irish adolescents. Journal of Adolescence, 29, 555-573.

Morgan, S.B., Walker, M., Bieberich, A., \& Bell, S. (1996). The Shared Activity Questionnaire. Unpublished manuscript, University of Memphis, Memphis, TN.

Naylor, P.B., Cowie, H.A., Walters, S.J., Talamelli, L., \& Dawkins, J. (2009). Impact of a mental health teaching programme on adolescents. The British Journal of Psychiatry, 194, 365-370.

Nowicki, E.A. (2006). A cross-sectional multivariate analysis of children's attitudes towards disabilities. Journal of Intellectual Disabilities Research, 50, 335-348.

Peterson, L., Mullins, L.L., \& Ridley-Johnson, R. (1985). Childhood depression: Peer reactions to depression and life stress. Journal of Abnormal Child Psychology, 13, 597-609.

Phelan, J.E., \& Basow, S.A. (2007). College students' attitudes toward mental illness: An examination of the stigma process. Journal of Applied Social Psychology, 37, 2877-2902.

Poster, E.C. (1992). Children's concepts of the mentally ill. Journal of Child and Adolescent Pediatric and Mental Health Nursing, 5, 28-36.

Roberts, M. C., Johnson, A.Q., \& Beidleman, W.B. (1984). The role of socio-economic status on children's perceptions of medical and psychological disorders. Journal of Clinical Child Psychology, 13, 243-249.

Swords, L., Hennessy, E., \& Heary, C. (2010a). Development of the Children's Attributions about Psychological Problems in their Peers (CAPPP) Scale. Child: Care, Health and Development. doi:10.1111/j.1365-2214.2010.01151.x.

Swords, L., Hennessy, E., \& Heary, C. (2010b). Adolescents' beliefs about sources of help for ADHD and depression. Journal of Adolescence. Epub ahead of print: doi:10.1016/j.adolescence.2010.06.002.

Wahl, O.F. (2002). Children's views of mental illness: A review of the literature. Psychiatric Rehabilitation Skills, 6, 134-158.
Walker, J.S., Coleman, D., Lee, J., Squire, P.N., \&Friesen, B.J. (2008). Children's stigmatization of childhood depression and ADHD: Magnitude and demographic variation in a national sample. Journal of the American Academy of Child andAdolescent Psychiatry, 47,912-920.

Wasserman, D., Cheng, Q., \& Jiang, G. (2005). Global Suicide rates among young people aged 15-10. World Psychiatry, 4, 114-120.

Weiner, B. (1995). Attribution theory in organizational behavior: A relationship of mutual benefit. In M.J. Martinko (Ed.), Attribution theory: An organizational perspective (pp. 3-6). Delray Beach, FL: St. Lucie Press.

Weiss, M.F. (1986). Children's attitudes toward the mentally ill: A developmental analysis. Psychological Reports, $58,11-20$.

Weiss, M.F. (1994). Children's attitudes toward the mentally ill: An eight-year longitudinal follow-up. Psychological Reports, 74, 51-56.

Weriserbs, B., \& Gottlieb, J. (2000). The effects of perceived duration of physical disability on attitudes of school children toward friendship and helping. Journal of Psychology, 134, 343-345.

Whalen, C.K., Henker, B., Dotemoto, S., \& Hinshaw, S.P. (1983). Child and adolescent perceptions of normal and atypical peers. Child Development, 54, 1588-1598.

WHO. (2004). Conclusions from pre-conference 'The Mental Health of Children and Adolescents', organised by European Commission, WHO European Region and the Ministry of Health of Luxemburg. Retrieved November 12, 2010, from http://ec.europa.eu/health/ph_determinants/life_style/mental/docs/ev_20040921_rd01_en.pdf

Woodward, R. (1995). The effects of gender and type of disability on attitudes of children toward peers with physical disabilities. Therapeutic Recreation Journal, 29, 219-227.

Accepted for publication: 7 September 2010

Published online: 11 January 2011

\section{Appendix: Sample vignettes ${ }^{1}$}

\section{$A D H D$}

Jake finds it very difficult to pay attention to what the teacher says and finds it difficult to concentrate on doing sums or reading or other work that the teacher gives him. Jake also finds it hard to stay sitting down when he is supposed to and often gets up or fidgets a lot. Often he has trouble waiting his turn in games and often interrupts when other people are doing things.

\section{Depression}

Lauren is an attractive girl who usually does okay in school. However, recently Lauren began to think that she is ugly, and not good at anything. She spends a lot of time thinking about all the things that she is not able to do and other sad thoughts. Sometimes she finds it hard to sleep at night so she is very often tired and upset during the day and cries a lot.

${ }^{1}$ There were four versions of each vignette: male and female, child peer and adolescent peer. The child peer versions of the two vignettes are presented here. 